NASA Technical Memorandum 105724

AIAA-92-3792

\title{
Use of an Approximate Similarity Principle for the Thermal Scaling of a Full-Scale Thrust Augmenting Ejector
}

Wendy S. Barankiewicz and Gail P. Perusek Lewis Research Center

Cleveland, $\mathrm{OH}$

and

Mounir B. Ibrahim

Cleveland State University

Cleveland, Ohio

Prepared for the

28th Joint Propulsion Conference

cosponsored by the AIAA, ASME, SAE, and ASEE

Nashville, Tennessee, July 6-8, 1992

\section{N/SN}


NASA Technical Memorandum

AIAA-92-3792

\section{Use of an Approximate Similarity Principle for the Thermal Scaling of a Full-Scale Thrust Augmenting Ejector}

Wendy S. Barankiewicz and Gail P. Perusek

Lewis Research Center

Cleveland, Ohio

and

Mounir Ibrahim

Cleveland State University

Cleveland, Ohio

Prepared for the

28th Joint Propulsion Conference

cosponsored by the AIAA, ASME, SAE, and ASEE

Nashville, Tennessee, July 6-8, 1992 


\title{
USE OF AN APPROXIMATE SIMILARITY PRINCIPLE FOR THE THERMAL SCALING OF A FULL-SCALE THRUST AUGMENTING EJECTOR
}

\author{
Wendy S. Barankiewicz", Gail P. Perusek* \\ National Aeronautics and Space Administration \\ Lewis Research Center \\ Cleveland, Ohio 44135 \\ Mounir Ibrahim ${ }^{* *}$ \\ Cleveland State University \\ Cleveland, Ohio 44115
}

\begin{abstract}
$\underline{\text { Abstract }}$
Full temperature ejector model simulations are expensive, and difficult to implement experimentally. If an appropriate similarity principle could be established, properly chosen performance parameters should be similar for both hot flow and cold flow model tests if the initial Mach numbers and total pressures of the flowfield are held constant. In this investigation, existing ejector data is used to explore the utility of one particular similarity principle -- the Munk and Prim similarity principle for isentropic flows. Static performance test data for a full-scale thrust augmenting ejector are analyzed for primary flow temperatures up to $1560^{\circ} \mathrm{R}$. At different primary temperatures, exit pressure contours are compared for similarity. A nondimensional flow parameter is then used to eliminate primary nozzle temperature dependence and verify similarity between the hot and cold flow experiments.
\end{abstract}

\section{Nomenclature}

$\begin{array}{ll}\mathrm{M} & =\text { Mach number } \\ \mathrm{NPR} & =\text { nozzle pressure ratio } \\ \mathrm{P} & =\text { pressure } \\ \mathrm{T} & =\text { temperature } \\ \gamma & =\text { specific heat ratio } \\ \phi & =\text { thrust augmentation ratio }\end{array}$

Subscripts

$\begin{array}{ll}\mathrm{p} & =\text { primary } \\ \mathrm{s} & =\text { secondary }\end{array}$

\footnotetext{
*Aerospace Engineer

${ }^{*}$ Assoc. Professor, Senior Member AIAA
}

$\begin{array}{ll}\mathrm{t} & =\text { total conditions } \\ 2 & =\text { diffuser entrance location } \\ 3 & =\text { diffuser exit location }\end{array}$

Introduction

An ejector is a mechanically simple pumping device consisting of a nozzle exhausting into a diffuser or shroud. Figure 1 highlights the main components and pertinent terminology of a simple ejector. Ejectors operate by inducing large amounts of air from the ambient through the entrainment action of the primary nozzle jet shear layer. Turbulent mixing of the two air streams accelerates the entrained air, increasing total mass flow and creating a force $(\mathrm{F}=\mathrm{ma})$ which results in an increase of thrust.

Several possible ejector applications are depicted in Figure 2. The Turbofan Forced Mixer or mixer ejector (Figure 2a) is used for noise suppression of a jet engine exit nozzle by mixing the core and fan flow before the nozzle exit. Pumping ejectors such as the turbine engine test installation (Figure 2b), act as mass flow augmentors to capture and expel free-jet flows. Thrust augmenting ejectors (Figure 2c) could provide vertical lift for short take-off and vertical landing (STOVL) aircraft. Here, air is ducted to a row of nozzles between the wing and fuselage of the aircraft. It is this third type of ejector application that will be discussed in this paper.

Although properly designed ejectors can perform very well with cool primary air, proposed technology results in 
elevated primary nozzle air temperatures. To examine specific performance effects, the NASA Lewis Research Center--in conjunction with Boeing Military Airplanes and Boeing de Havilland--have tested a full-scale lift ejector at primary flow temperatures ranging from ambient to $1100^{\circ} \mathrm{F}$, and primary nozzle pressure ratios up to 3.0. This unique ejector testing, performed at the NASA Lewis Research Center's Powered Lift Facility (PLF); signifies the first design point (both pressure and temperature) testing of a full-scale thrust augmenting ejector. Figure 3 shows the top view (secondary flow inlet) of the full-scale experimental model as installed on the PLF. For experimental purposes, the model was turned on its side, measuring thrust in the axial direction (parallel to the ground plane).

The cost and complexity of testing ejector models could be greatly reduced if one could neglect temperature effects of the primary nozzle when determining ejector performance. Theoretically, this could be accomplished if a suitable jet similarity principle could be established. An approximate technique has been used by Greitzer, Patterson, and Tan [ref. 1] for viscous heat conducting flows (mixer ejector nozzles). Basically, this technique states that for fixed geometry and inlet total pressure distributions, the Mach number and total pressure along the streamlines are independent of the upstream total temperature distribution. This is an extension of the Munk and Prim Principle [ref. 2] for steady isentropic flows, where the current approach includes the nonisentropic (viscous) effects.

The purpose of this paper is to examine the cold and hot experimental ejector data and assess the validity of an approximate similarity principle (Munk \& Prim) for this application. Results presented will include thrust augmentation, normalized pumping, Mach number and total pressure profiles. The degree of dependence of the normalized ejector performance on the primary nozzle total temperature is examined.

\section{Experimental Apparatus \& Procedure}

\section{$\underline{\text { Facility }}$}

The Powered Lift Facility is a triangular shaped thrust frame, multi-directional force measuring system and dry air supply. The three sides of the thrust stand are 30 feet long and 15 feet above ground level. There are six load cells capable of measuring thrust levels in the lateral ( 0 to $\left.5,000 \mathrm{lb}_{\mathrm{f}}\right)$, vertical (0 to $\left.25,000 \mathrm{lb}_{\mathrm{f}}\right)$, and axial ( 0 to $5,000 \mathrm{lb}_{\mathrm{f}}$ ) directions as well as the moments of roll, pitch, and yaw. The test hardware can be full-scale and weigh up to $35,000 \mathrm{lbs}$.

Air enters the test section at a maximum pressure of 150 psig, and can be supplied to the test hardware at ambient temperatures to simulate fan jet airflow or heated to $1200^{\circ} \mathrm{F}$ by means of a J-58 burner can supplied with JP5 fuel, to simulate engine exhaust conditions. Flow measurement is accurate to within $\pm 0.5 \%$ including both scatter and systematic errors. The maximum allowable line pressure and flow rate at the test section is 90 psig and 150 pps, respectively. Ground effects of the exhaust flow are negligible.

$\underline{\text { Model }}$

The ejector model is an array of ten notched-cone nozzles (primary flow) placed chordwise (the $\mathrm{x}$-direction in Figure 2c) along the throat of a converging/diverging nozzle shroud. Each of these primary nozzles has three spanwise (the y-direction in Figure 2c) convergent nozzle exits. Diffuser exit plane data collection was obtained spanwise with a single pressure/temperature rake traversed in the chordwise direction. See Figure 3 for a view of the inlet, and Figure 4 for the exit plane. During the experiment, several model configuration changes were made to increase performance. For simplicity, data from only one configuration was analyzed with the similarity principle. Figure 5 depicts the inlet geometry of this configuration. All data was obtained using the same configuration, however the plywood spacer was removed when lighting the burner to allow for the thermal expansion of the nozzles.

\section{Procedure}

Steady-state performance testing consisted of pressure, temperature, and thrust measurements over a nozzle pressure ratio (NPR) range of 1.6 to 3.0. These runs were conducted with primary flow temperatures of $1560^{\circ} \mathrm{R}, \quad 1360^{\circ} \mathrm{R}, \quad 1160^{\circ} \mathrm{R}$, and a cold flow of approximately $530^{\circ} \mathrm{R}$ (temperature of facility air supply without the burner ignited). For the hot temperatures, the steady state max-to-min temperature variation was approximately $\pm 20^{\circ} \mathrm{R}$ based on the burner system capability. The cold flow primary temperature did not vary as much during each test run; however, since the PLF is an outdoor facility, primary and secondary air temperatures are lower for the tests conducted in the winter months than in the summer. For more detailed information regarding the experiment and model, see Reference 3. 


\section{Munk and Prim Similarity Principle}

In the prediction of hot ejector flow, a similarity principle that could eliminate the primary nozzle temperature effect on performance, would reduce testing costs and complexity by eliminating the need to conduct experiments at elevated temperatures. If the energy exchange due to viscous stresses could be neglected and the flow thus considered isentropic, the Munk and Prim Similarity Principle would apply [ref. 2]. This principle is valid for steady, adiabatic, inviscid flow of a perfect gas with constant specific heats.

Simply stated, the Munk and Prim Principle is a guiding philosophy which says: For a fixed geometry and upstream total pressure profile, any change in the upstream total temperature profile does not alter the streamline shapes, Mach number or total pressure distributions (and therefore momentum) in the device. This can be seen by inspection of the governing equations for isentropic, compressible flow written in terms of the Mach number and pressure [ref. 1].

Continuity:

$$
\nabla \cdot \vec{M}\left[1+\frac{(\gamma-1)}{2} \vec{M}^{2}\right]^{\frac{-(\gamma+1)}{2(\gamma-1)}}=0
$$

Momentum:

$$
(\vec{M} \cdot \nabla) \vec{M}-\frac{\gamma-1}{\gamma+1} \vec{M}(\nabla \cdot \vec{M})+\frac{1}{\gamma} \nabla \ln (P)=0
$$

Momentum expressed in terms of total pressure:

$$
\begin{aligned}
& (\vec{M} \cdot \nabla) \vec{M}-\left(\frac{\gamma-1}{\gamma+1}\right) \vec{M}(\nabla \cdot \vec{M})+ \\
& -\left(\frac{1}{\gamma-1}\right) \nabla\left[\ln \left(1+\frac{\gamma-1}{2} \vec{M}^{2}\right)\right]+\frac{1}{\gamma} \nabla \ln \left(P_{t}\right)=0
\end{aligned}
$$

Because continuity \& momentum are decoupled from the energy equation (total enthalpy or total temperature does not appear), the Mach number and static and total pressure fields are unchanged with respect to changes in upstream total temperature. The streamline pattern is also unchanged. In other words, a change in total temperature affects only the local velocity, while keeping the relative distributions constant.

In an ejector, energy is exchanged by momentum transfer in the viscous shear layer. This violates the inviscid flow assumption, so in a strict sense the original Munk and Prim analysis is not applicable. However,expanding the concept of this similarity principle to include the ejector problem would be a logical first approximation. Even though this is only an approximate technique, studies by Greitzer, Patterson, and $\operatorname{Tan}^{1}$ and Presz ${ }^{4}$ show that there is very little decrease in augmentation ratio with temperature ratio increase.

\section{$\underline{\text { Results and Discussion }}$}

In this discussion, ejector performance is measured by the thrust augmentation ratio:

$$
\Phi=\frac{\text { total thrust }}{\text { primary-nozzle ideal thrust }}=\frac{\text { load cell measurement }}{\text { isentropic thrust }}
$$

where isentropic thrust is computed from internal nozzle static pressure taps and the supply pipe mass flow rate.

Constant pressure performance curves of the present data [Figure 6] show a thrust augmentation loss as the primary nozzle temperature increases. The augmentation levels of the two curves--representing different ambient temperatures--differ by approximately $2 \%$. It is interesting to note that similar amounts of reduction in the augmentation ratio can take place by (1) decreasing the secondary flow temperature by about $30^{\circ} \mathrm{R}$, or (2) increasing the primary nozzle temperature by about $500^{\circ} \mathrm{R}$. Supporting this result is Figure 7 [ref. 5], which includes the experimental results of eight different ejectors. All the data from the literature shows a slight temperature dependence of the ejector, and although all the data--except that of Lockheed-- included a scale or configuration change, the trend is consistent.

Now that it has been established that the trends of the present ejector data fit that from the literature, the first step in the Munk and Prim analysis involved comparing exit plane Mach number and total pressure profiles of the cold and hot primary flow experiments. For a truly inviscid flow these profiles should stay constant when changing the primary nozzle total temperature. Since Mach number and total pressure exit plane distributions are quite similar, redundant plots will not be presented.

The chordwise Mach number distribution [Figure 8] was calculated at each location as the average of the spanwise exit rake values. Although end effects are present, similarity between the two different primary 
nozzle total temperature datasets can be seen. Other than lowering the local peak values, the change in primary nozzle total temperature did not significantly change the Mach number distribution.

A typical contour plot obtained from the exit rake data is shown in Figure 9. Here the cold flow total pressure distribution is plotted across the entire exit plane $(\mathrm{NPR}=2.7)$. The contour shows the overall trends and locations of each nozzle exit, however, lacks smoothness due to the interpolation of the plotting routine. To smooth the contours and eliminate any end effects/boundary layer effects, we then looked at the center third of the duct.

Figure 10 shows the hot and cold primary nozzle pressure comparison for the center portion of the duct $(\mathrm{NPR}=2.7)$, where approximately three and a half nozzle plumes are visible across the chord length. As expected, the contours are definitely similar, however there are a few discrepancies due to experimental error and duct thermal expansion. The qualitative similarity of the pressure distributions suggests that the Approximate Munk and Prim principle may be applicable for the thermal scaling of this ejector's performance characteristics.

To investigate the Munk and Prim concept further, it is necessary to obtain a nondimensional parameter that would collapse both the hot and cold flow performance curves into one. Since the Munk and Prim principle is only an interpretation of the governing equations, a specific parameter to use for ejector applications must be obtained by other means. As derived by Presz [ref. 4], a control volume analysis for ejector performance under ideal conditions (incompressible, isentropic) yields:

$$
\begin{aligned}
& \frac{T_{t_{s}}}{T_{t_{p}}}\left(\frac{\dot{m}_{s}}{\dot{m}_{p}}\right)^{2}\left[\left(\frac{A_{p}}{A_{s}}\right)^{2}+\left(\frac{A_{2}}{A_{3}}\right)^{2}\right] \\
& +2 \sqrt{\frac{T_{t_{s}}}{T_{t_{p}}}}\left(\frac{\dot{m}_{s}}{\dot{m}_{p}}\right)\left[1+\left(\frac{A_{2}}{A_{3}}\right)^{2}\right] \\
& +\left[\left(\frac{A_{2}}{A_{3}}\right)^{2}-1-2\left(\frac{A_{s}}{A_{p}}\right)\right]=0
\end{aligned}
$$

It is clear that an appropriate nondimensional parameter is the ejector pumping ratio

$$
\frac{\dot{m}_{s}}{\dot{m}_{p}} \sqrt{\frac{T_{t_{s}}}{T_{t_{p}}}}
$$

which is only a function of ejector geometry. Although this equation has been derived for low speed flow, compressible flow would follow the same trend.

Figure 11 demonstrates the usefulness of the nondimensional pumping parameter. Here, part (a) of the figure shows the mass flow ratio as a function of the primary to secondary pressure ratio for different primary total temperatures at a constant flow area ratio $\left(A_{s} / A_{p}\right)$. Note, as expected from the control volume analysis, the pumping parameter is fairly constant with respect to changes in the total pressure ratio. Part (b) of the figure shows that the normalized pumping parameter collapses the results such that the temperature effects drop out.

Since the normalized pumping parameter "washes out" the jet temperature effects, it seems an appropriate factor to use in characterizing ejector performance. For ideal flow the thrust augmentation ratio can be expressed as:

$$
\phi=1+\left(\frac{M_{s}}{M_{p}}\right)\left[\frac{\dot{m}_{s}}{\dot{m}_{p}} \sqrt{\frac{T_{t_{f}}}{T_{t_{p}}}}\right]
$$

Basically, this is a control volume equation where the pressure-area terms were neglected in an order of magnitude approximation. At first glance it may appear that the ideal flow thrust augmentation ratio varies with the normalized pumping parameter. However, since the Mach number ratio is constant through the Munk and Prim principle and the normalized pumping parameter is only a function of ejector geometry, then the thrust augmentation ratio should be invariant with the normalized pumping parameter. In Figure 12 the thrust augmentation ratio was plotted against the normalized pumping parameter. There is slight scatter in the data and it shows only a small dependence on the pumping parameter. A linear Least Squares regression was invoked on both the hot and cold data. The correlation is as follows:

$$
\phi=1.813-(0.052) \frac{\dot{m}_{s}}{\dot{m}_{p}} \sqrt{\frac{T_{t_{s}}}{T_{t_{p}}}}
$$

where the "goodness of fit" parameter has a value of 0.7 , 
and a perfectly linear correlation would have a value of 1.0. Some of the scatter could be explained as experimental error. Other effects that may contribute to the scatter, are the incomplete mixing of the primary and secondary flows and the performance loss caused by the wall viscous effects [ref. 3].

For the same geometry and inflow total pressure distribution, the expectation is that (based on the Munk and Prim similarity principle) the normalized ejector performance should exibit no dependence on total temperature (momentum and energy effects are contained in the normalization). Figure 12 illustrates the relationship between the thrust augmentation ratio and the normalized (with respect to temperature) ejector pumping parameter. The data reflects a very weak dependency between these two parameters and thus this data supports the fundamental premise of the approximate Munk and Prim similarity principle. The excursion of the data from the proposed ideal slope (Fig. 12) has a consistent trend for both cold and hot temperatures. Such departures are probably manifest in the fact that the experiment involves considerable flow nonidealities. Therefore, for this ejector, hot flow performance can be approximated by cold flow data according to the Approximate Munk and Prim principle with only a slight over prediction.

\section{Concluding Remarks}

The similarity between hot and cold flow experiments was confirmed for existing full-scale thrust augmenting ejector data. The present experimental data showed a $4 \%$ decrease in augmentation ratio for a primary nozzle temperature increase of $1000^{\circ} \mathrm{R}$, while supporting data from the literature showed that cold air jets may overpredict the thrust augmentation ratio by approximately 2-3\%. Consistent with the Munk and Prim similarity principle, the total pressure and Mach number distributions for different primary nozzle total temperatures were found to be quite similar. Thus, for a first cut approximation, the Munk \& Prim Similarity Principle holds for this ejector configuration and shows that temperature effects are relatively small and compensating, even when there is substantial viscous and heat transfer effects. An ejector pumping parameter was used to eliminate the temperature dependence in the performance curves. The end result is that cold flow tests can be used to obtain a rough prediction of hot flow results at reduced time, cost, and complexity.

\section{$\underline{\text { References }}$}

1. Greitzer, E.M.; Patterson, R.W.; and Tan, C.S.: An Approximate Substitution Principle for Viscous Heat Conducting Flows. Proc. R. Soc. London, vol. A401, no. 1820,1985 , pp. $163-193$.

2. Munk, M.; and Prim, R.C.: On the Multiplicity of Steady Gas Flows Having the Same Streamline Pattern. Proc. Nat. Acad. Sci., vol. 33, no. 5, 1947, pp. 137141.

3. Barankiewicz, W.S.: Static Performance Tests of a Flight-Type STOVL Ejector. NASA TM-104437, 1991.

4. Presz, W.M.; and Greitzer, E.M.: A Useful Similarity Principle for Jet Engine Exhaust System Performance. AIAA Paper 88-3001, July 1988.

5. Bevilaqua, P.M.: Advances in Ejector Thrust Augmentation. AIAA Paper 84-2425, Oct. 1984. 


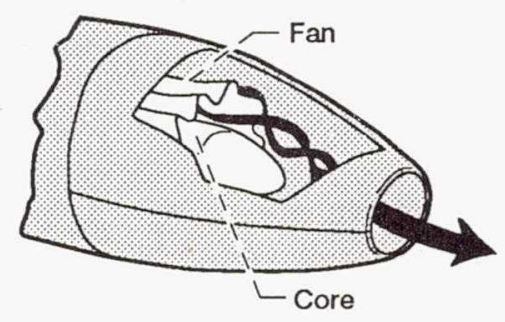

(a) Turbofan forced mixer.

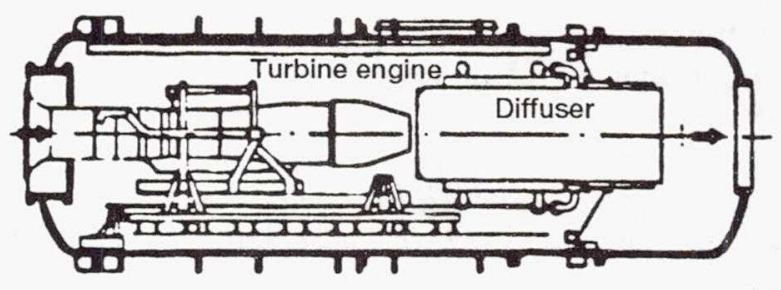

(b) Typical turbine engine test installation.

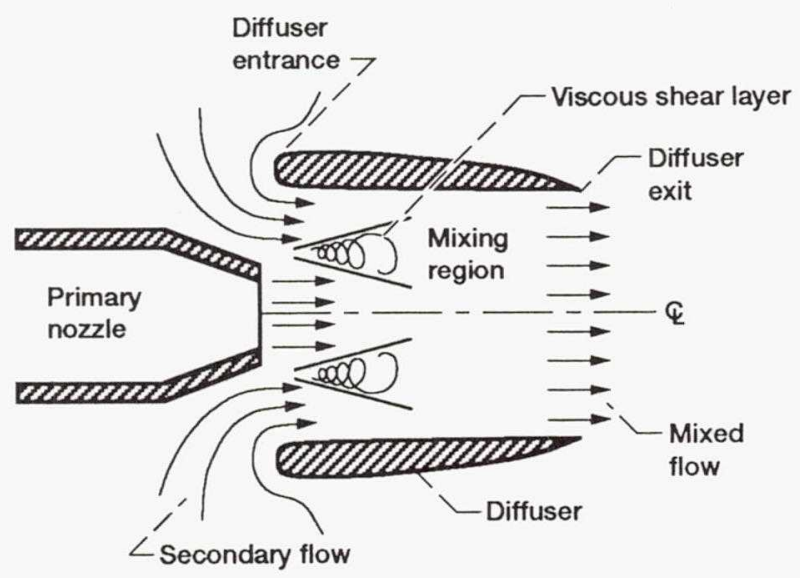

Figure 1.-Simple ejector schematic.

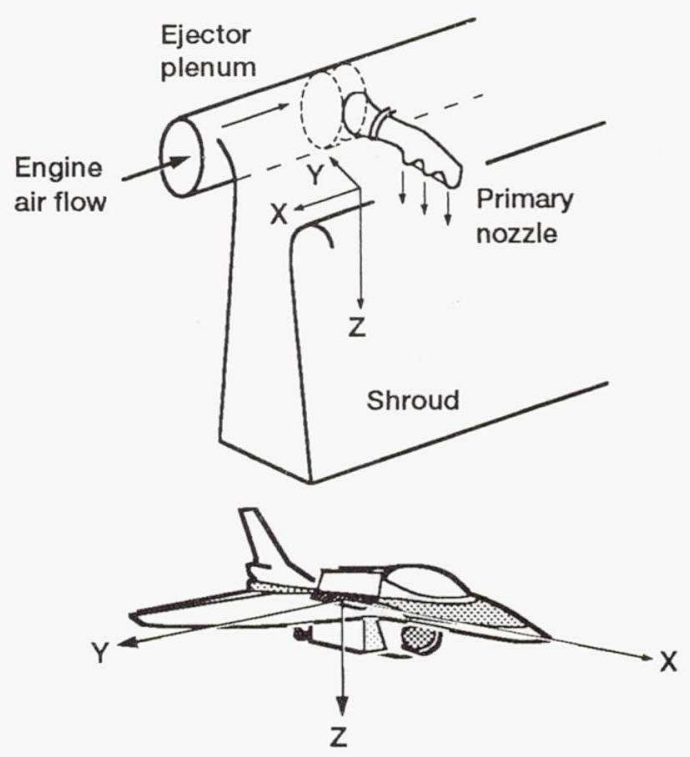

(c) Vertical lift aircraft configuration.

Figure 2.-Ejector applications. 


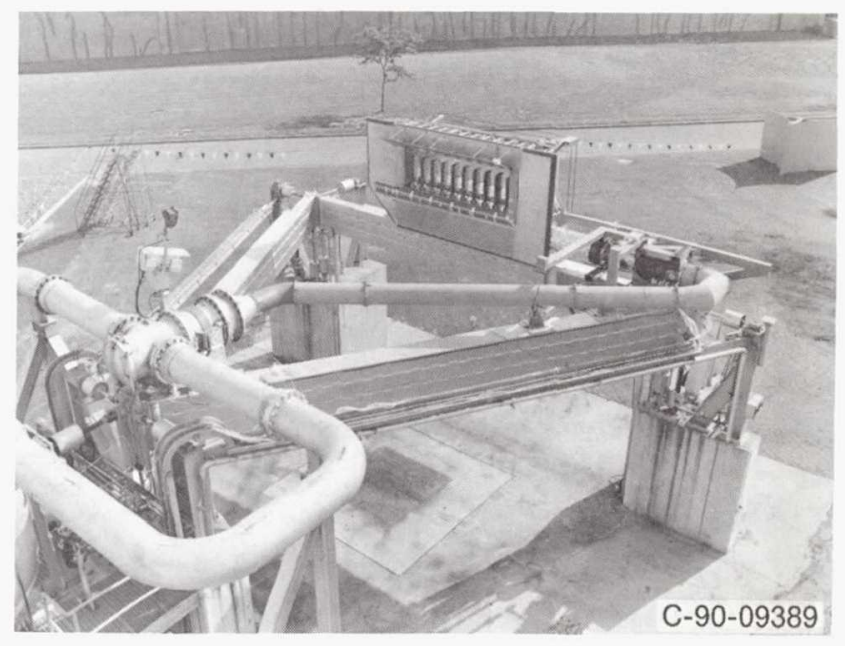

Figure 3.-Ejector installed on the PLF.

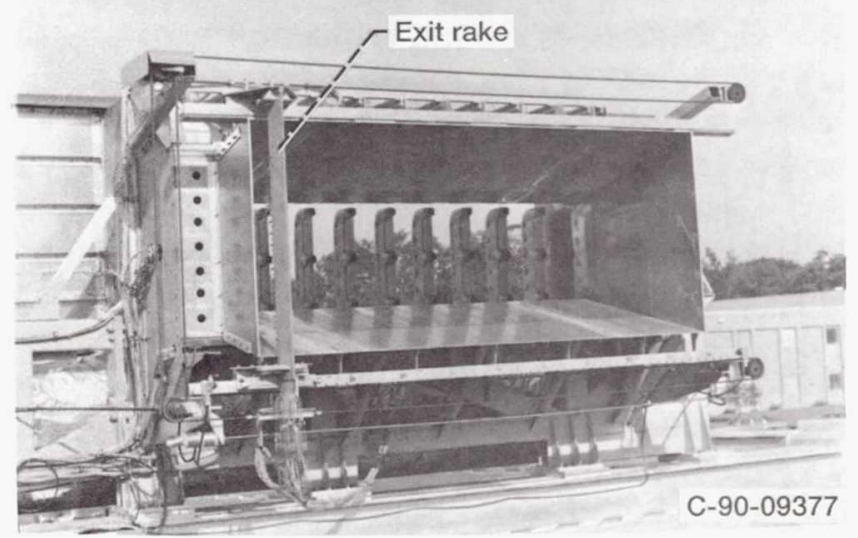

Figure 4.-Ejector exit plane.

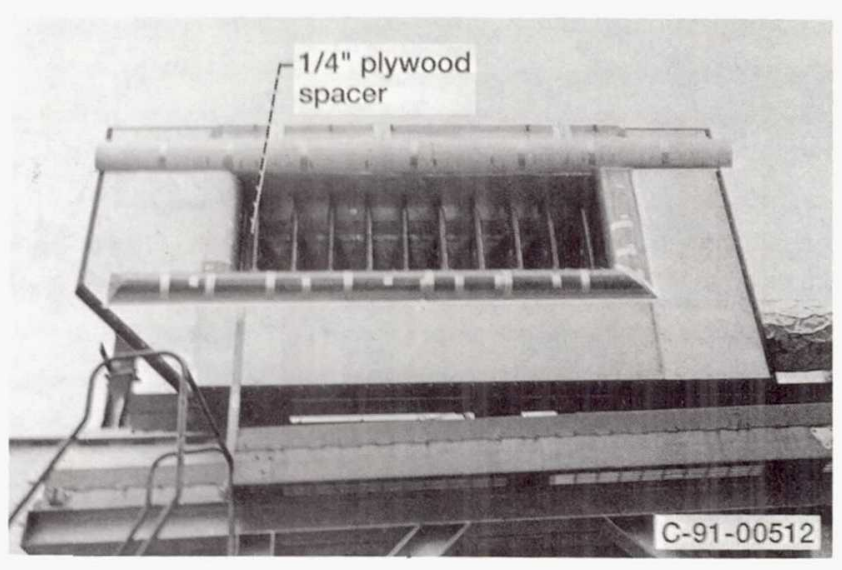

Figure 5.-Experimental configuration used in analysis. 


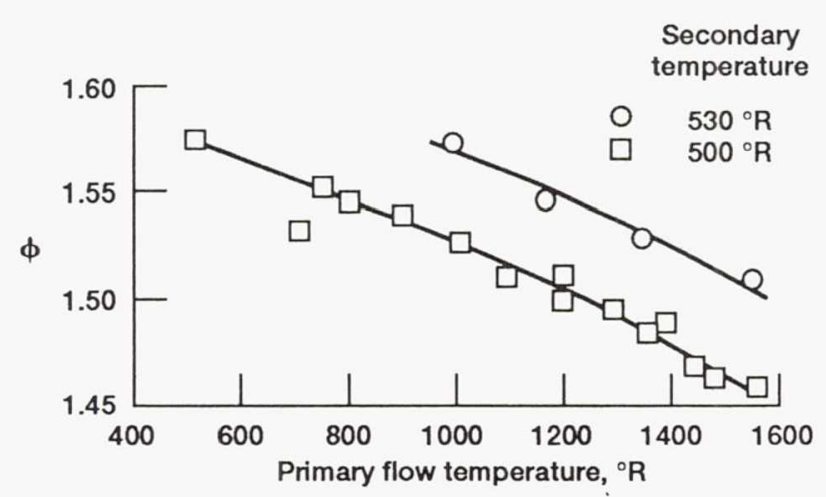

Figure 6.-Ejector performance at NPR $=2.7$.

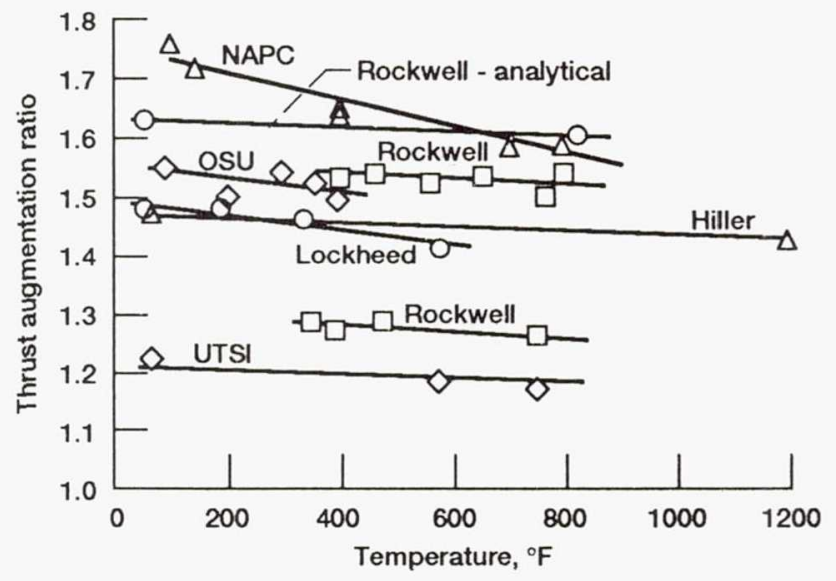

Figure 7.-Effect of temperature on ejector thrust augmentation. From: Bevilaqua, P.M., "Advances in Ejector Thrust Augmentation", AIAA 84-2425, 1984.

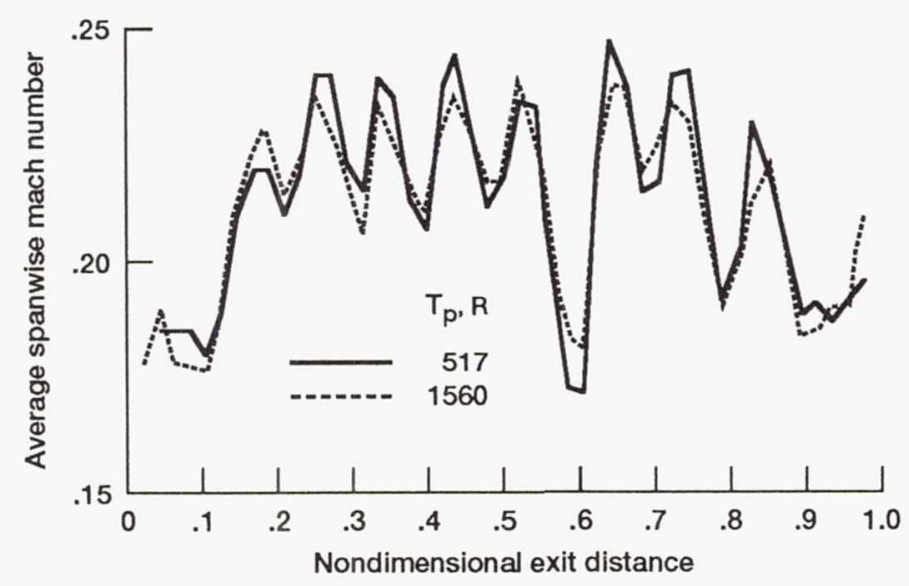

Figure 8.-Chordwise ejector exit Mach number distributions. 


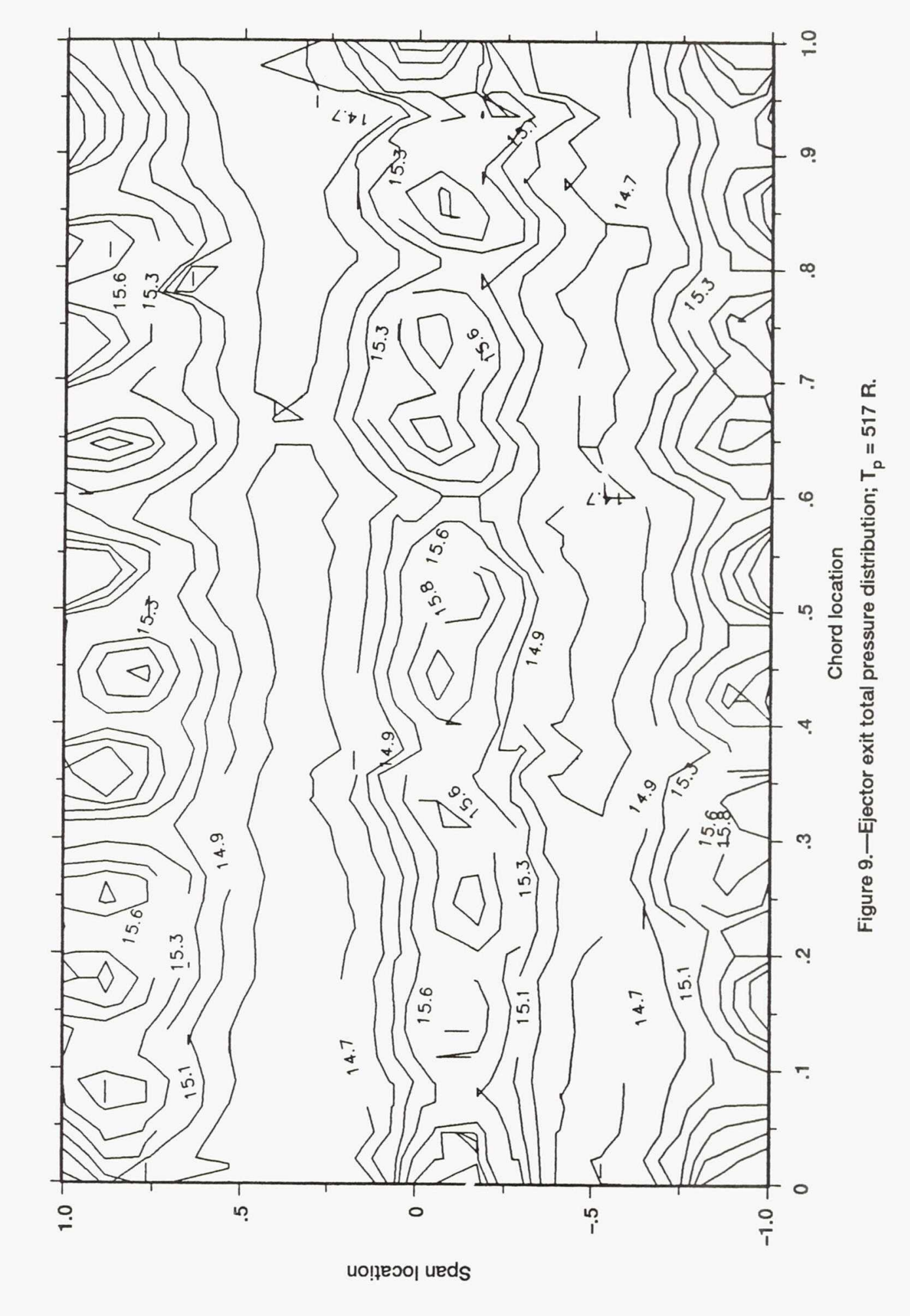




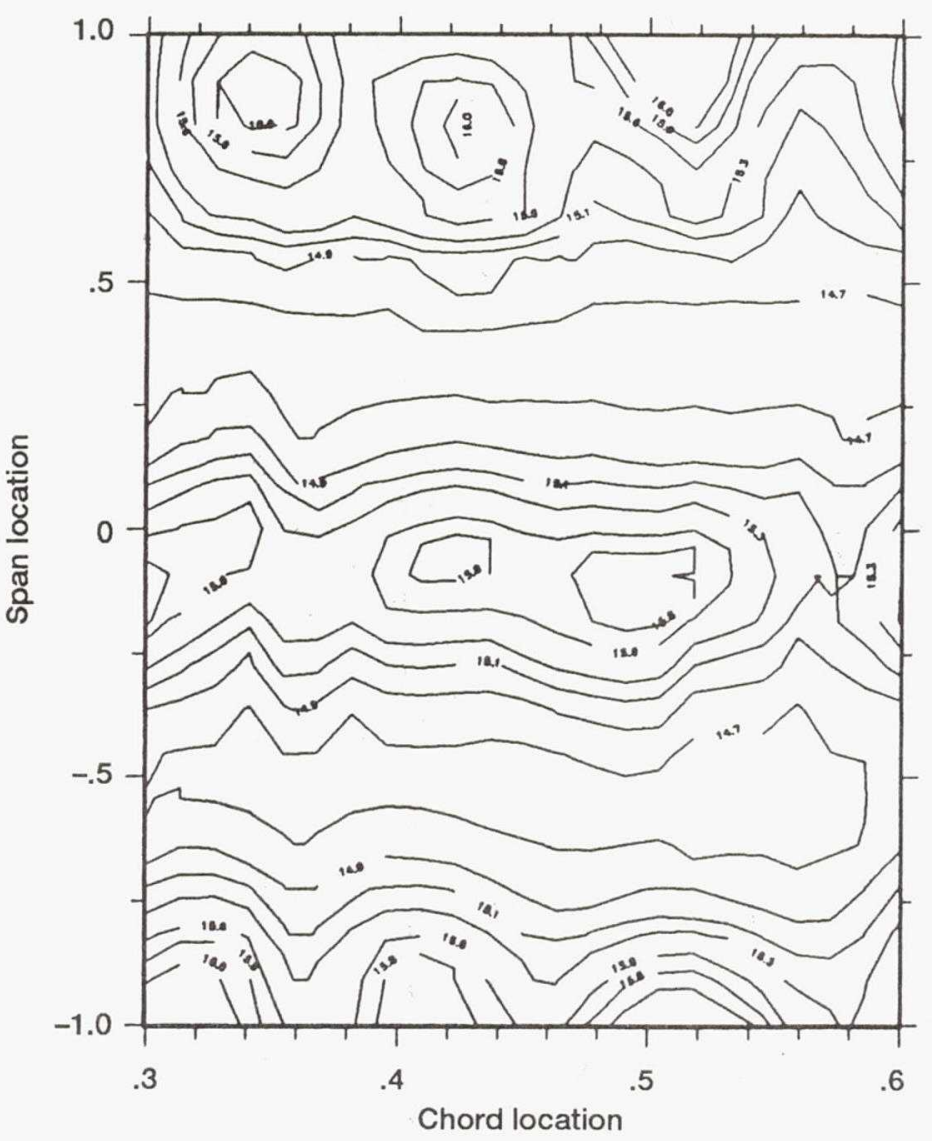

(a) $T_{p}=517 R$.

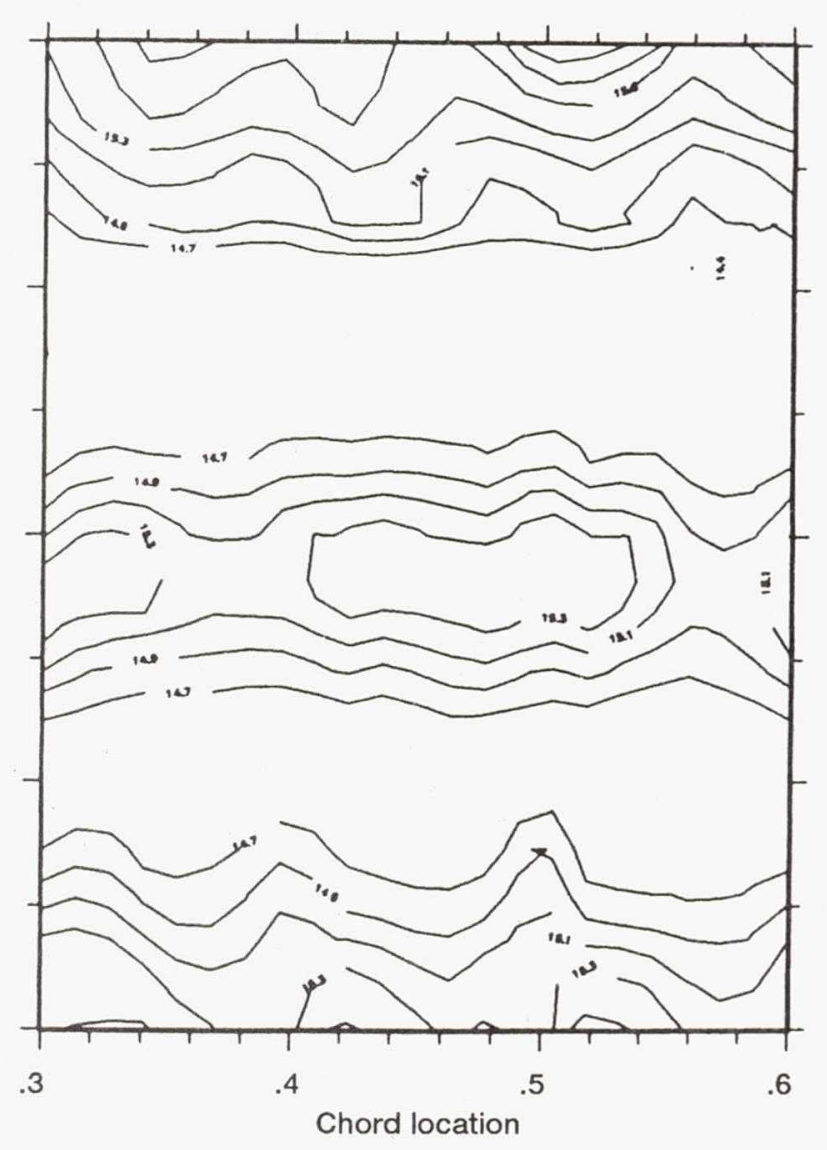

(b) $T_{p}=1560 R$.

Figure 10.-Total pressure distribution: center nozzles. 


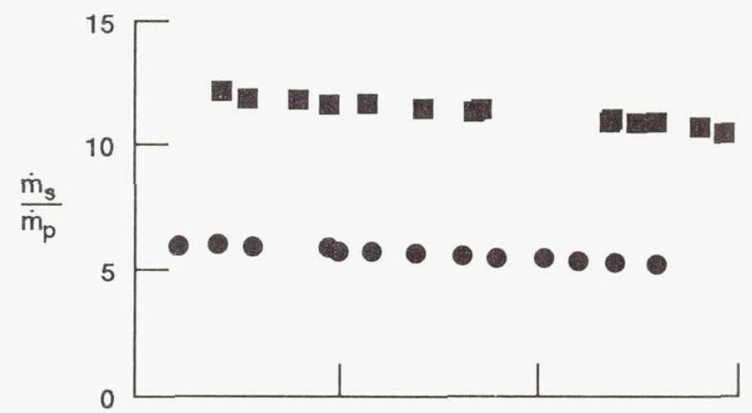

(a) Nondimensional mass flow vs. pressure.

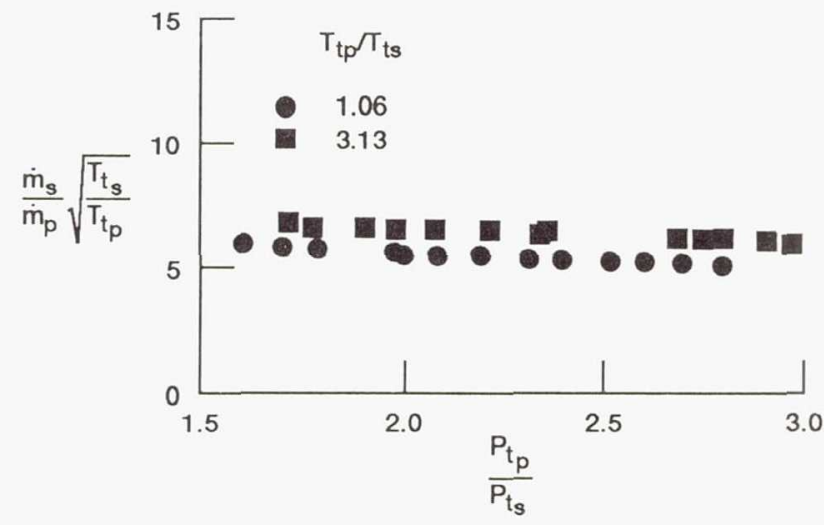

(b) Normalized pumping parameter vs. pressure.

Figure 11.- Normalized pumping parameter at constant ejector area ratio.

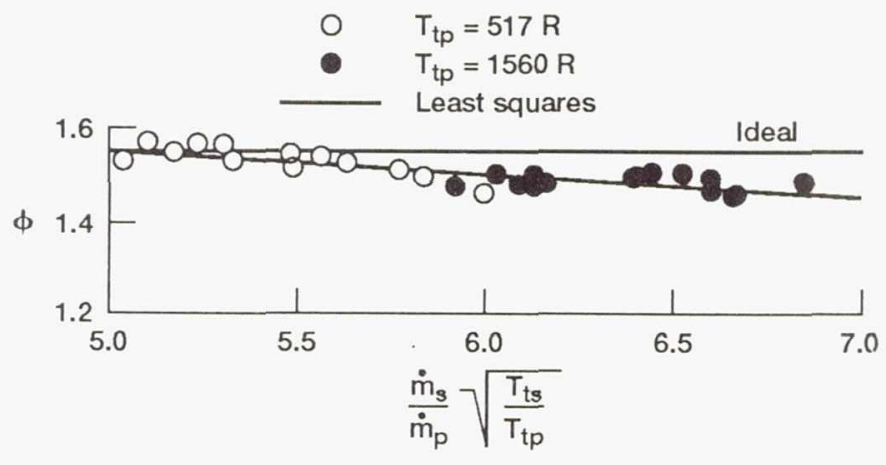

Figure 12.-Performance versus nondimensional flow. 
Public reporting burden for this collection of information is estimated to average 1 hour per response, including the time for reviewing instructions, searching existing data sources, gathering and maintaining the data needed, and completing and reviewing the collection of information. Send comments regarding this burden estimate or any other aspect of this collection of information, including suggestions for reducing this burden, to Washington Headquarters Services, Directorate for information Operations and Reports, 1215 Jefferson Davis Highway, Suite 1204, Arlington, VA 22202-4302, and to the Office of Management and Budget, Paperwork Reduction Project (0704-0188), Washington, DC 20503.

\begin{tabular}{|l|l|l|}
\hline 1. AGENCY USE ONLY (Leave blank) & $\begin{array}{c}\text { 2. REPORT DATE } \\
\text { July } 1992\end{array}$ & $\begin{array}{r}\text { 3. REPORT TYPE AND DATES COVERED } \\
\text { Technical Memorandum }\end{array}$ \\
\hline
\end{tabular}

4. TITLE AND SUBTITLE 5. FUNDING NUMBERS

Use of an Approximate Similarity Principle for the Thermal Scaling of a

Full-Scale Thrust Augmenting Ejector

6. AUTHOR(S)

WU-505-62-71

Wendy S. Barankiewicz, Gail P. Perusek, and Mounir B. Ibrahim

7. PERFORMING ORGANIZATION NAME(S) AND ADDRESS(ES)

8. PERFORMING ORGANIZATION REPORT NUMBER

National Aeronautics and Space Administration

Lewis Research Center

Cleveland, Ohio 44135-3191

E-7124

9. SPONSORING/MONITORING AGENCY NAMES(S) AND ADDRESS(ES)

10. SPONSORING/MONITORING AGENCY REPORT NUMBER

National Aeronautics and Space Administration

Washington, D.C. 20546-0001

NASA TM-105724

\section{SUPPLEMENTARY NOTES}

Prepared for the 28th Joint Propulsion Conference cosponsored by AIAA, ASME, SAE, and ASEE, Nashville, Tennessee, July 6-8, 1992. Wendy S. Barankiewicz and Gail P. Perusek, NASA Lewis Research Center, Cleveland, Ohio; Mounir Ibrahim, Cleveland State University, Cleveland, Ohio. Responsible person, Wendy S. Barankiewicz, (216) 433-8706.

12a. DISTRIBUTION/AVAILABILITY STATEMENT 12b. DISTRIBUTION CODE

Unclassified - Unlimited

Subject Category 07

13. ABSTRACT (Maximum 200 words)

Full temperature ejector model simulations are expensive, and difficult to implement experimentally. If an appropriate similarity principle could be established, properly chosen performance parameters should be similar for both hot flow and cold flow model tests if the initial Mach numbers and total pressures of the flowfield are held constant. In this investigation, existing ejector data is used to explore the utility of one particular similarity principle - the Munk and Prim similarity principle for isentropic flows. Static performance test data for a full-scale thrust augmenting ejector are analyzed for primary flow temperatures up to $1560{ }^{\circ} \mathrm{R}$. At different primary temperatures, exit pressure contours are compared for similarity. A nondimensional flow parameter is then used to eliminate primary nozzle temperature dependence and verify similarity between the hot and cold flow experiments.

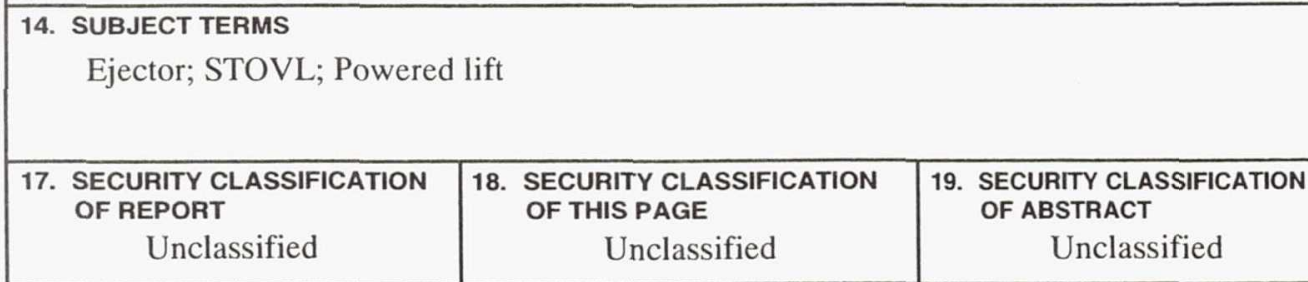

